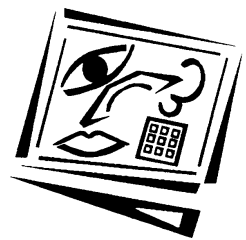

\title{
Revisiting the impact of formative assessment opportunities on student learning
}

\author{
Mary Peat and Sue Franklin \\ University of Sydney \\ Marcia Devlin \\ Swinburne University of Technology \\ Margaret Charles
University of Sydney
}

\begin{abstract}
This project developed as a result of some inconclusive data from an investigation of whether a relationship existed between the use of formative assessment opportunities and performance, as measured by final grade. We were expecting to show our colleagues and students that use of formative assessment resources had the potential to improve performance of first year students. This first study, undertaken in semester 1 2002, indicated that there was no apparent relationship between the two, even though the students reported how useful they found the formative assessment resources. This led us to ask if there was a transition effect such that students were not yet working in an independent way and making full use of the resources, and/or whether in order to see an effect we needed to persuade non-users of the resources to become users, before investigating if use can be correlated with improvement in performance. With the 2002-3 NextEd ASCILITE Research Grant we set out to repeat our project and to look at use and usefulness of resources in both first and second semester, to encourage nonusers to become users and to investigate the relationship between use and performance. Now our story has a different ending.
\end{abstract}

\section{Introduction}

The teaching and learning environment in undergraduate science in Australian higher education is one that requires the simultaneous management of large numbers of students, increasing student expectations and shrinking resources (Franklin \& Peat, 1998; 2001). In relation to assessment of learning, these expectations are pressing: trend data over a five year period indicates that forty percent of Australian first year university students do not believe they receive helpful feedback on their progress from teachers (McInnis, James \& Hartley, 2000). 
In an attempt to address some of these issues, a mixture of online and offline learning and assessment resources have been developed in first year biology at the University of Sydney (Peat \& Franklin, 2002; 2003). The assessment resources include both formative and summative items, some with the provision of extensive feedback to individual students. In order to provide flexibility of access and opportunity for independent study, many of these resources are available online through a Virtual Learning Environment (VLE - http:/ / fybio.bio.usyd.edu.au/VLE/L1/) (Franklin \& Peat, 2001) and are also available on a CD.

An advantage of online resources is that they are available for use by students any time and any place. In this way, students can be provided with the feedback they are now requesting and this may help them in their final assessment tasks. The development of online assessment resources has a number of advantages over offline pen and paper tasks. The former can be easily marked, often automatically, and provide instant feedback to large numbers of students. If so designed, online assessments can be taken repeatedly by students in order to assess and improve their performance. In addition, online tests can be taken unsupervised in students' own time. It has been shown that online assessments allow students to tailor their use to their own learning style (Clariana, 1997) and that the use of online formative assessment prior to summative tests can reduce student anxiety (Zakrzewski \& Bull, 1999). One example of the contribution of formative computer based assessment to improvements in student learning outcomes is documented by Buchanan (2000) who found that undergraduate psychology students who used an online formative assessment package that provided instant feedback performed better in the end of course summative assessment than those who did not use the package.

While online assessment materials may help meet demands for flexibility in time, place and pace, use limited resources effectively and be enjoyable for users, the ultimate purpose of such assessment resources should be to impact positively on student learning outcomes. A previous study, undertaken within first year biology at the University of Sydney during semester 1 in 2002, found there was no apparent evidence of any impact of online and offline formative and summative assessment opportunities on student learning (Peat \& Franklin, 2003).

Intriguingly, at least some of the students who participated in this study perceived the use of online assessment resources as beneficial to their learning despite the fact that there was no differential effect of the use of the resources on their performance (Peat \& Franklin, 2003). This is intriguing because the literature shows that students who make use of every learning opportunity approach the final assessment tasks with a greater likelihood of high performance outcomes (eg. De Vita, 2001; 
Heffler, 2001). More specifically, studies have indicated that the use of formative tests before summative examinations increases the grade point of students (Buchanan, 2000; Zakrzewski \& Bull, 1999). The University of Sydney is providing a variety of formative assessment resources to first year biology students that would appear to contain relevant feedback, yet these resources have not been shown to be having the desired impact on student learning outcomes for all students.

The present study aimed to re-examine the question of whether using the formative assessment resources provided in first year biology had any impact on user learning outcomes. In particular, the issue of a possible 'transition effect' on student use of resources and/or learning outcomes was of interest. More specifically, it was proposed that previous findings indicating no impact of online and off line summative assessment opportunities on student learning might have been due to the fact that the sample of students who participated in the study were in transition to university. Data collected in second, rather than first, semester of the first year of university study, was expected to show a higher level of student self direction to use the available resources.

This study investigates whether non-users of formative assessment opportunities could be persuaded to become users and, if so persuaded, whether there was there an impact on their learning outcomes. In order to facilitate usage, the value of using the available resources was emphasised during both semesters to all students. The ways in which this emphasis occurred is detailed below, following a description of each of the four resources and student feedback on each one.

\section{Assessment resources}

The assessment resources provided for first year biology students at the University of Sydney fall into several classification categories - online and offline (paper based); summative assessment (compulsory) and formative assessment (non-compulsory); supervised (undertaken in class time) and non-supervised (undertaken in students' own time). More information about the resources can be found in Peat and Franklin (2003). In the current study, use of the non-compulsory formative material provided to the students was of interest. The material included:

- $\quad$ self assessment modules;

- a mid course practice examination;

- weekly paper based self test quizzes; and

- crossword puzzles. 


\section{Self assessment modules}

Self assessment modules are designed to draw together related parts of the course to help students make connections between topics in biology and to promote a deeper approach to learning (Biggs, 1987), whilst providing an enjoyable feedback and reinforcement session. The modules allow students to identify their level of understanding and consolidate learning, whilst working at their own pace in their own time. The most recent discussion about the development and evaluation of these modules can be found in Peat (2000), Franklin and Peat (2001), and Peat and Franklin (2002).

When asked how they thought these modules helped their learning in biology, a small group of students $(n=7)$ interviewed for this study by an external consultant not involved in teaching or assessing biology students, generally agreed that the modules "showed us the sort of questions to expect". All seven students agreed that the modules helped with revision of topics and provided a way to test understanding in an interactive way "as opposed to passively reading a textbook". The interactivity of the modules was referred to several times: "it's a dynamic way to do things"; "it adds colour and interaction"; "it's more fun".

When asked how these interactive features helped their learning one student reported that "they help you sift through the reading" explaining further that they provided a guide to what was important in the textbook. Another student commented, "I played with the CD modules straight away when I got them and all through [the semester] and tested myself at the beginning and throughout". A third reported, "I studied for them, then used them to test my knowledge" and indicated that this strategic use of the modules had helped her "a lot".

It should be noted that the group interviewed were not representative of all first year biology students nor was the group of a sufficient size so that generalisations might be made. However, student responses to the interview questions provided some indication of the ways in which the resources were viewed by students.

\section{Mid course practice examination}

The mid course practice examination is paper based, taken in class time and administered under examination conditions in order to give the students as close to the 'real' examination experience as possible. The students mark their scripts in their own time from an online version. To gain feedback on their answers, students use the online version in an interactive way, by entering their answers and having the program mark their performance and give them feedback where appropriate. The feedback is aimed at helping students identify their understanding of 
course concepts, which in turn might indicate the need for some remedial action. The practice examination also helps reduce the stress about end of course examinations, and hopefully, allows students to achieve at a higher level in the final assessment than would otherwise have been the case. Students perceived to be 'at risk' are encouraged to use online revision materials, designed to enhance student understanding of major topic areas.

When asked how using this resource had helped their learning, several of the seven students interviewed reported that it helped them determine their strengths and weaknesses in biology - "[you] know what you remember and what to study". One student reported that studying for the practice exam helped to break up the textbook reading for her. She explained that the preparation for the mid course examination gave her a focus - she went through the textbook and "strategically studied bits that were important". The same student suggested that the marked exam provided "automatic study notes" for later use. Another student agreed, reporting that the answers on the web were "the best thing" because they were so thorough and that they were also a study resource. All seven students interviewed agreed that the "prac exam" helped to consolidate and reinforce their learning, give them a taste of what doing an exam felt like and would be like in terms of format and content, and helped them determine which areas they needed to know more about.

\section{Weekly paper based self test quizzes}

The weekly quizzes were provided at the end of each week's practical notes. Each short quiz consists of multiple choice and short answer questions designed to help students self appraise their performance. The questions are similar to those in the formal examinations and weekly summative quizzes. Answers are provided both online via the VLE and offline in the Biology Learning Centre which is a room in the first year biology building.

The seven students interviewed indicated that the quizzes helped their learning in a number of ways including "reinforcing of what's just been done", ensuring "you really knew what had happened in the lab". One student explained, "The labs are so full. It's hard to sift out what's important, what happened, what the point was. You do three activities sometimes six or seven activities - and you're not sure what the points are. You think to yourself, 'Why are we doing this?'" Other students agreed and as one put it, "[The quizzes] provide the basis of the main points of what you've done in the labs".

Other learning benefits, from the students' point of view were that "the questions are a link between lectures and pracs"; "[The quizzes] are good 
examples of MCQs you expect will be on the exam" and "they are good preparation for the weekly [assessed] computer quizzes". One student felt that "Because they are marked on the VLE and you get feedback, this means you have an automatic study tool".

The students found these so useful they suggested their use be extended to include additional questions (to those specific to that lab) that call for revision on previous lab(s). It was suggested that hard copies of the answers be placed in the Biology Learning Centre and further that model answers (hard copy and online) be provided as a means for students to check whether they are "on the right track with the way we are answering". As one student explained - "this would be really good feedback".

\section{Crossword puzzles}

The aim of introducing crosswords was to provide a fun exercise that would give students a "quiz" on some of the course content, in order to help them identify areas of weakness. In particular, the crosswords contained clues pertaining to definitions and terminology. Each crossword was handed out in a practical session to be completed in the laboratory or at home. It was expected that most students would use this type of resource individually and that not all students would choose to use them as they were provided as a non-compulsory learning/revision resource. Solutions are provided on the VLE two weeks after the crossword puzzle has been handed out.

With the exception of one student, the interviewees felt these were "fun"; "interactive"; "better than going over the text book" and overall, most useful for testing their understanding of definitions and for revision. One student explained their attraction thus: "if something is fun, it increases your motivation and lightens up study". Another agreed, adding, "you get so sick of reading and then you can't remember what you've read and you think, 'Oh dear me....'". One student indicated the crosswords were perceived as a challenge - "a personal challenge to finish" which another student felt each one "forces you to think about what you've learnt".

\section{Emphasis on assessment resources}

After a detailed consideration of student interview responses as well as first year biology teaching staff reflections on the summative resources, it was determined that despite the seemingly discouraging responses from the earlier study (Peat \& Franklin, 2003), the resources seemed to hold potential for improving student learning outcomes and that this potential should be explored. 
As a result of the information from the 2002 study (Peat \& Franklin, 2003), it was decided that in an attempt to highlight the value of the materials available to assist student learning, the amount of information about the resources available for helping students with their study of biology would be increased and integrated into student material in 2003. Additional information was included in the student notes in semester 1, and some small activities were added in the early lab sessions. At the beginning of semester 2 a flyer was produced and handed out to all students. It was hoped that these interventions would act as "triggers" to alert the students to the value of the resources. Each intervention is described in detail below.

\section{Intervention 1}

For semester 1, rather than create yet another sheet of paper or page in the lab book highlighting what there was and why it could be useful, the information was given to the students in the context of the course and interweaved into the lab notes and the lab session activities:

- In order to familiarise the students with the electronic resources, in week 2 of semester 1, a tour of the Virtual Learning Environment (VLE) and Biology CD was provided for the students. This was an activity undertaken in peer groups during a practical session. The students worked at the laboratory computers and investigated the VLE web site, and answered a series of questions that were written in the lab notes. Then, if they had their CD with them, they could investigate its contents and answer questions about the possible uses of the various resources;

- In week 3, the weekly self test quiz had information added which directed students to answers, which were available electronically in the VLE and on paper in the Biology Learning Centre. This was to encourage the students to use the formative quizzes and check their answers; and

- At the end of each week's lab activities there was an Independent Study section in the notes, reading and questions to be answered in preparation for the next week's work. Additions were made to this section so that it highlighted which electronic learning and self assessment modules in the VLE and on the CD were useful for the (current) topics of study.

Intervention 2

At the end of semester 1, 2003, students were surveyed, using quantitative and qualitative questions, about their use and perceptions of usefulness of resources. A focus group interview with a sample of students was held, as mentioned above, by an external consultant to gather student views about the usefulness of biology assessment resources. The interview was designed both to determine why some students did not use these items and 
the perceived usefulness of the items to those who chose to use them. Students were asked how using each of the item(s) helped their learning in biology and how they thought the item could be enhanced to better help their learning. The student responses led to the development of a colourful information flyer (Appendix 1) that could be used to advertise the resources.

At the beginning of semester 2 all students were given the flyer entitled "Want to improve your marks in Biology??" that advertised the various resources available as well as tips for making best use of them. This flyer was handed out in laboratory classes and was posted on all noticeboards and biology staff office doors. It was intended that the flyer might encourage non-users of the learning resources to become users during second semester.

At the end of second semester the students were re-surveyed as to their use and perceptions of usefulness of the learning resources. What was of particular interest was whether any non-users in semester 1 became users in semester 2, possibly as a result of the promotion of the resources and whether this affected their performance. One of the research questions asked was, "Did non-users of formative assessment resources who became users improve their exam performance?". The answer to this research question may help to answer the broader question, "Has student learning been improved by the use of online and offline formative assessment opportunities?" posed in Peat and Franklin (2003).

As much of first year biology teaching is to students who are unlikely to continue with a biological education because they are enrolled in other degree programs (eg Nursing, Pharmacy), it was expected that a student's level of interest in biology might affect whether or not $\mathrm{s} /$ he used the assessment resources which in turn might affect performance. The study sought to examine whether or not there was a relationship between interest in the discipline, use of the available resources and performance.

Each survey collected student demographics, including university entry score, prior experience of biology at secondary school and a rating of their current interest in the study of biology. Participation was voluntary. Perceptions of the usefulness of resources were investigated using a four point scale, with students classifying statements according to whether they used a resource, found it not useful, useful or extremely useful. Open ended questions asked students why they had not used a resource (if relevant) and in what way the resource helped them in their learning (if they had used it). These open ended responses were thematically analysed and categorised (Denzin \& Lincoln, 1994). The outcomes of this part of the project are not reported here except to indicate that their responses are very 
similar to those in the previous study (Peat \& Franklin, 2003). Student performance was measured by their final examination mark, which included multiple choice and short answer questions.

The implementation of the survey complied with the University of Sydney's Ethics Committee Guidelines for research with humans and this enabled the authors to seek permission to correlate performance with usage/non-usage of materials and with perceptions of usefulness.

\section{Results and discussion}

\section{Demographics}

Survey 1 was handed out to all students in class time in semester 1 . The response rate was $72 \%$. The students responding to the survey were considered to be representative of the entire cohort $(n=1435)$ in that $69 \%$ of respondents were female and $31 \%$ male (the total class cohort is $66 \%$ female and $34 \%$ male); and $53 \%$ were in Science degrees (67\% for the entire cohort). Further, the demographics of the 2003 cohort were similar to that of the 2002 cohort (Peat \& Franklin, 2003).

Survey 2 was handed out to all students in class time in semester 2 . The response rate was $62 \%$. The demographics of respondents in semester 1 were similar to that of respondents in semester 2 .

\section{Intervention 1}

Use of formative assessment resources increased slightly from 2002 to 2003 (Table 1). For example the use of self assessment modules increased from $79 \%$ to $82 \%$; use of self test quizzes in the practical notes increased from $82 \%$ to $86 \%$; and the use of crossword puzzles increased from $72 \%$ to $77 \%$. These increases may reflect an enhanced appreciation of the existence from the beginning of the semester of the resources due to the increased information and activities (Intervention 1) that were provided within the context of the first few weeks of teaching and learning.

Table 1: Comparison of the use of resources across two years

\begin{tabular}{|l|c|c|c|}
\hline & $\begin{array}{c}2002 \\
\text { sample }\end{array}$ & $\begin{array}{c}2003 \text { sample } \\
\text { semester 1 }\end{array}$ & $\begin{array}{c}2003 \text { sample } \\
\text { semester 2 }\end{array}$ \\
\hline $\begin{array}{l}\text { Self Assessment Modules (SAMs) on the } \\
\text { VLE or CD }\end{array}$ & $79 \%$ & $82 \%$ & $89 \%$ \\
\hline $\begin{array}{l}\text { Self test quiz available for each practical } \\
\text { session }\end{array}$ & $82 \%$ & $86 \%$ & $86 \%$ \\
\hline Crossword puzzles & $72 \%$ & $77 \%$ & $74 \%$ \\
\hline
\end{tabular}




\section{Intervention 2}

The flyer (Intervention 2) was used to help increase awareness of the learning resources at the beginning of semester 2 . It was found that there was little difference from semester 1 to semester 2 in usage of self test quizzes and crossword puzzles between semesters in 2003 but an increase of $5 \%$ in the use of SAMs, which translates into approximately 85 more students (in the whole cohort) using this resource in semester 2 than in semester 1 .

\section{Use of SAMs}

On the basis of the information in Table 1 on the increase in the use of formative assessment resources and in particular the data on usage of SAMs that indicated an increase from 79\% usage in semester 12002 to $89 \%$ usage in semester 2 2003, it was decided to look more critically at the use of SAMs and whether this use had any influence on student performance.

Non-users of SAMs who became users

One question of interest was whether non-users in semester 1 who became users in semester 2 had moved their position within their cohort when compared to other students. University Admissions Index (UAI) and examination results for both semesters were available for 388 students, who did not differ significantly from the average for the cohort in either semester. The second semester examination marks tended to be lower overall than those for first semester, so to make comparisons across semesters more meaningful, marks were first standardised within each semester for all available student data. The conversion to $\mathrm{z}$-scores sets the mean of each semester examination marks to zero, and an individual's mark then represents the number of standard deviations their mark is from the mean, with above average marks represented by positive z-scores and below average marks represented by negative z-scores. The information captured by the z-scores can be interpreted as relative position within the cohort of 897 semester 1 students, and 811 semester 2 students for whom examination data were available.

The group of interest comprised those students who were non-users of SAMs in semester 1 and became users in semester 2 . Therefore, the 388 students were classified into two groups: those who changed to users $(n=48)$, and all others $(n=340)$. Students who changed from non-users to users had significantly higher tertiary entrance scores (UAI mean $=92.0 \mathrm{vs}$ 89.4 for all others, $\mathrm{t}_{386}=2.12, \mathrm{p}=.04$ ), so to control for possible confounding effects of academic ability, UAI was entered as a covariate into the analysis. A $2 x(2)$ analysis of covariance with repeated measures on examination $z-$ scores compared those students who changed to users to all other students. 
Mean $z$-scores were 0.29 in the semester 1 examination and 0.03 in the semester 2 examination for those who changed from non-users to users, and 0.12 and 0.04 respectively for others. Although both groups showed a slight decrease in relative standing, the change was not statistically significant overall across groups $\left(\mathrm{F}_{1,385}=1.74, \mathrm{p}>.05\right)$. Those students who changed to users did not differ significantly from all others in either relative standing $\left(\mathrm{F}_{1,385}=0.68, \mathrm{p}>.05\right)$, or change in relative standing $\left(\mathrm{F}_{1,385}=\right.$ $1.98, \mathrm{p}>.05)$. UAI was a significant predictor of examination marks, as might be expected for first year university students $\left(\mathrm{F}_{1,385}=216.9, \mathrm{p}<.001\right)$.

Overall, it seems that changing from non-user to user of SAMs cannot be directly related to corresponding changes in grades. However, the number of students who fell into the group classified as changing in this manner was relatively small.

All student users of SAMs versus non-users

In order to evaluate the potential benefits of SAMs, the performances of students who made use of the resources were compared to the performances of students who did not make use of them. The use of SAMs was recorded as a dichotomous variable. In the following analyses, hierarchical regression analyses were carried out for each semester's raw examination mark, first controlling for ability by entering UAI, then investigating whether use of SAMs could be shown to increase performance over and above the contribution of ability. For semester 1, the examination was out of 108 marks and for semester 2 the examination was out of 98 marks.

Data were available for 692 students for semester 1, including 548 users and 144 non-users of SAMs. For the semester 1 examination, UAI made a statistically significant contribution to performance, accounting for $27.6 \%$ of variability in examination marks, but use of SAMS was essentially unrelated to performance, with no change in the proportion of variability accounted for $\left(\mathrm{F}_{1,689}=0.09, \mathrm{p}=.76\right)$.

For the analysis of semester 2 results, data were available for 588 students, including 518 users of SAMs and 70 non-users. In the semester 2 examination, the use of SAMs made a statistically significant contribution to performance $\left(\mathrm{R}^{2}=.27\right.$ for UAI, $\mathrm{p}<.001$; increasing to $\mathrm{R}^{2}=.28$ with SAMs, $\left(\right.$ DeltaR $\left.{ }^{2}=.01, \mathrm{~F}_{1,585}=6.33, \mathrm{p}<.05\right)$. In terms of examination performance, the benefit of using SAMs can be understood as a difference in marks: amongst those of the same ability, students using SAMs scored on average 3.96 marks higher in the second semester examination than those who did not use SAMs. 
The differences between results from semesters 1 and 2 may be due to a wide range of possible influences. Just by the nature of time and experience, by semester 2 many first year students are more settled into the patterns of university study and life than they were in their first semester. It is likely that with increased familiarity with and understanding of the systems and requirements of university level study, factors in addition to ability (as indicated by UAI) may increasingly come into play in terms of student learning outcomes. It is possible that by semester 2, some students have begun to employ a range of strategies and resources available to help their study and that these are having a positive impact on their learning. These suggestions are, of course, speculative only, but further investigation into the possible benefits of using SAMS seems warranted.

Science students versus other students

Science students were the largest group within the cohort of students studying biology (approximately 56\% in both semesters). There were students from other domains (e.g. Nursing, Pharmacy) whose participation in biology was compulsory at the junior level, but who may not have had a great deal of interest in the subject matter. Performance in a subject area might be expected to vary not only as a function of ability, but also of interest in the area. It is possible that those students who are more interested in a subject may make more use of available resources, and it may be that the interest drives performance rather than the resources per se. Students rated their interest in biology in each semester on a scale of 1 ('not at all interested') to 5 ('very interested').

The performance of Science students is of particular interest, as these are the students for whom the SAMs were designed in the first place, being the students most likely to continue with the subject area. Science students are more homogeneous in ability (as indicated by UAI) than the other students who study biology, so that factors other than ability may be more relevant for success in examinations. Effects of interest, ability and SAM usage on examination performance were investigated separately for Science students and other students. Table 2 shows the results of the hierarchical regression analyses predicting examination performance from UAI (a percentile ranking), interest in biology (scored $1-5)$, and use of SAMs (no/yes), separately for Science and other students.

The final model was statistically significant in each case. For Science students in semester $1, \mathrm{R}^{2}=.21, \mathrm{~F}_{3,393}=33.7$, semester $2, \mathrm{R}^{2}=.18, \mathrm{~F}_{3,346}=24.7$; for other students in semester $1, R^{2}=.38, F_{3,292}=59.24$, semester $2, R^{2}=.46$, $\mathrm{F}_{3,234}=66.6$.

The relationship between UAI and performance in examinations was somewhat attenuated amongst Science students given the greater 
homogeneity of UAIs, and ability accounted for 11.7 to $13.4 \%$ of variability in performance in examinations compared to 35.8 to $41.3 \%$ for other students. Interest in biology was a significant predictor of examination performance for all students in both semesters, with higher levels of performance associated with higher levels of interest. The use of SAMs made an independent contribution to examination performance in the second semester for Science students but not for those of other faculties. For Science students of the same ability and same level of interest in biology, there was a statistically significant increase in semester 2 examination performance, equivalent to an increase of 4.6 marks, associated with the use of SAMs.

Table 2: Regression analyses predicting examination performance

\begin{tabular}{|c|c|c|c|c|c|c|c|c|}
\hline \multirow{2}{*}{\multicolumn{2}{|c|}{ Semester and step }} & \multirow{3}{*}{$\begin{array}{l}\text { Predictor } \\
\text { UAI }\end{array}$} & \multicolumn{3}{|c|}{ Science students } & \multicolumn{3}{|c|}{ Other students } \\
\hline & & & \multirow{2}{*}{$\begin{array}{c}\begin{array}{c}\text { B at } \\
\text { entry }\end{array} \\
.80\end{array}$} & \multirow{2}{*}{$\begin{array}{c}\text { DeltaR }^{2 b} \\
.134\end{array}$} & \multirow{2}{*}{$\begin{array}{c}\mathrm{p} \\
<.01\end{array}$} & \multirow{2}{*}{$\begin{array}{c}\begin{array}{c}\text { B at } \\
\text { entry }\end{array} \\
1.00\end{array}$} & \multirow{2}{*}{$\begin{array}{c}\text { DeltaR }^{2 ~ b} \\
.358\end{array}$} & \multirow{2}{*}{$\begin{array}{c}\mathrm{P} \\
<.01\end{array}$} \\
\hline Sem 1 & Step 1 & & & & & & & \\
\hline & Step 2 & Interest & 3.79 & .071 & $<.01$ & 2.38 & .020 & $<.01$ \\
\hline & Step 3 & SAMs use & -1.04 & .001 & n.s. & 1.12 & .001 & n.s. \\
\hline \multirow[t]{3}{*}{ Sem 2} & Step 1 & UAI & .74 & .117 & $<.01$ & 1.06 & .413 & $<.01$ \\
\hline & Step 2 & Interest & 2.84 & .047 & $<.01$ & 3.48 & .047 & $<.01$ \\
\hline & Step 3 & SAMs use & 4.60 & .012 & $<.05$ & -0.56 & .000 & n.s. \\
\hline
\end{tabular}

a. $B$ is the unstandardised regression coefficient, and indicates the predicted change in performance with an increase of 1 unit in the predictor variable, controlling for other variables already entered.

b. DeltaR ${ }^{2}$ is the change in the proportion of variability in performance accounted for.

\section{Implications for teaching and learning}

The results of this study confirm that ability (as indicated by UAI) is a strong predictor of performance in first year university study. While most first year teachers would be aware of this, studies such as this can serve as a reminder that the ability playing field is not level and that efforts to improve teaching and learning should acknowledge this reality. With respect to this current study it would appear that the use of resources designed to help students in their new independent learning environment do not appear to have any effect on performance in the first semester of their university studies, as indicated by the performance effect of the use of SAMs. This is supported by the previous study (Peat \& Franklin, 2003) in which no evidence was found of any impact of online and offline formative and summative assessment opportunities on student learning. However, this lack of impact is not evident in second semester where the use of SAMs has a significant effect on performance. Thus it may be that there is a transition effect in which students, whilst using formative assessment 
resources in first semester, are not yet able to benefit fully from this type of resource because it requires a certain level of independence. It may be that in first semester students are not yet sufficiently critical of their own performance to benefit from the resources.

This study also demonstrated that level of interest in biology can predict examination performance. This, too, may be unsurprising to most teaching academics, whatever the field or discipline. However, interest, unlike ability, can be relatively easily increased. Teacher enthusiasm, efforts to continually demonstrate the relevance of biology to students' experiences, lives and futures, and the use of imaginative and illustrative examples of concepts are a few of the myriad strategies that can be used to engage student interest.

The most encouraging outcome of this study is that for Science students both their level of interest in the discipline and their use of SAMs can improve performance amongst those of the same ability. Encouraging students to use the available SAMS, with their dynamic, interactive, "fun" instructive learning based format is likely to increase their enjoyment of and interest in the subject. Ultimately, and most importantly, as this study has shown, encouraging use of the assessment resources is likely to improve student learning outcomes as indicated by their performance, whatever their ability or likelihood of continuing their study of biology.

\section{Acknowledgements}

Part of this work was funded by the 2002-3 NextEd ASCILITE Research Grant awarded to two of the authors (SF \& MP).

\section{References}

Biggs, J. (1987). Student approaches to learning and studying. Melbourne, Australia: Australian Council for Educational Research.

Buchanan, T. (2000). The efficacy of a World-Wide Web mediated formative assessment. Journal of Computer Assisted Learning, 16, 193-200.

Clariana, R. B. (1993). A review of multiple-try feedback in traditional and computer based instruction. Journal of Computer Based Instruction, 20(3), 76-74.

Denzin, N. K., and Lincoln, Y. S. (Eds) (1994). Handbook of qualitative research. Thousand Oaks, CA, USA: Sage Publications.

De Vita, G. (2001). Learning styles, culture and inclusive instruction in the multicultural classroom: A business and management perspective. Innovation in Education and Training International, 38(2), 165-174. 
Entwistle, N. J., Hounsell, C. J., Macaulay, C., Situnayake, G. \& Tait, H. (1989). The Performance of Electrical Engineers in Scottish Education. Report to the Scottish Education Department, Centre for Research on Learning and Instruction Department of Education, University of Edinburgh.

Franklin, S. \& Peat, M. (1998). Strategies to support learning and student progression: The first year biology way. Proceedings of the Third Pacific Rim Conference - First Year in Higher Education: Strategies for Success in Transition Years, Auckland, New Zealand, (Vol II 37/1-10). [verified 26 Oct 2004] http://www.qut.edu.au/talss/fye/papers98/SF-MP98.DOC

Franklin, S. \& Peat, M. (2001). Managing change: The use of mixed delivery modes to increase learning opportunities. Australian Journal of Educational Technology, 17(1), 37-49. http://www.ascilite.org.au/ajet/ajet17/franklin.html

Heffler, B. (2001). Individual learning style and the Learning Style Inventory. Educational Studies 27(3), 307-316.

McInnis, C., James, R. \& Hartley, R. (2000). Trends in the First Year Experience in Australian Universities. A project funded by the Evaluations and Investigations Programme, Higher Education Division, DETYA. Canberra: Australian Government Printing Service. [11 Sep 2002, verified 26 Oct 2004]. http://www.detya.gov.au/archive/highered/eippubs/eip00_6/fye.pdf

Peat, M. \& Franklin, S. (2002). Supporting student learning: The use of computerbased formative assessment modules. British Journal of Educational Technology, 33(5), 517-526.

Peat, M. \& Franklin, S. (2003) Has student learning been improved by the use of online and offline formative assessment opportunities? Australian Journal of Educational Technology 19(1), 87-99, http://www.ascilite.org.au/ajet/ajet19/peat.html

Zakrzewski, S. \& Bull, J. (1999). The mass implementation and evaluation of computer-based assessments. Assessment E Evaluation in Higher Education, 23(2), 141-152.

\section{Appendix}

\section{Want to improve your marks in Biology??}

Research shows that using a range of learning resources is related to better exam performance. Have you taken advantage of all these resources?

- Mid-semester practice exam (in VLE)

- Self- Assessment Modules (in VLE \& on CDROM)

- Self-test quizzes (in lab notes, answers in VLE)

- Crossword puzzles (handed out in labs, answers in VLE)

Successful students indicate the resources are useful because: 
- They reinforce learning; help revise for tests and exams

- They help identify areas where more study is needed

- They re good preparation and practice for exams

- They are fun

Tips for making the best of the resources:

- Make time on a regular basis to use the resources (a little bit of time each week is all that is needed)

- Ask for help early if having Internet/access problems

- Don $t$ forget most of the resources are on the CDROM

- Don $t$ forget there s FREE Internet access to the VLE in the Resource Centre (room 507) Carslaw

Have fun while you are using the resources (this is compulsory!)

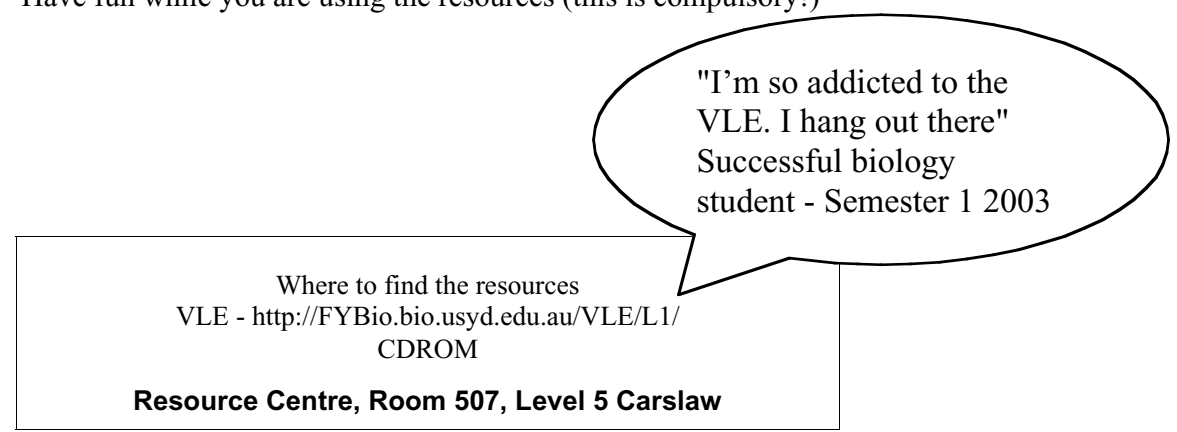

This article received an Outstanding Paper Award at ASCILITE 2004, gaining the additional recognition of publication in AJET (with minor corrections). The reference for the Conference version is:

Peat, M., Franklin, S., Devlin, M. \& Charles, M. (2004). Revisiting associations between student performance outcomes and formative assessment opportunities: Is there any impact on student learning? In R. Atkinson, C. McBeath, D. JonasDwyer \& R. Phillips (Eds), Beyond the comfort zone: Proceedings of the 21st ASCILITE Conference (pp. 760-769). Perth, 5-8 December.

http://www.ascilite.org.au/conferences/perth04/procs/peat.html

Mary Peat \& Sue Franklin, School of Biological Sciences, University of Sydney, NSW 2006, Australia. Email: maryp@bio.usyd.edu.au, sue@bio.usyd.edu.au Marcia Devlin, Higher Education Division, Swinburne University of Technology, Victoria 3122, Australia. Email: mdevlin@swin.edu.au

Margaret Charles, School of Psychology, University of Sydney, NSW 2006, Australia. Email: margretc@psych.usyd.edu.au 